\title{
A cold-air cyclogenesis study using a potential vorticity inversion method
}

\author{
By DOMINIQUE LAMBERT ${ }^{1 *}$, PHILIPPE ARBOGAST ${ }^{2}$, JEAN-PIERRE CAMMAS $^{1}$, \\ JÉRÔME DONNADILLE ${ }^{1}$ and PATRICK MASCART ${ }^{1}$ \\ ${ }^{1}$ Laboratoire d'Aérologie, Observatoire Midi-Pyrénées, Toulouse, France \\ ${ }^{2}$ CNRM, Météo-France, Toulouse, France
}

\section{SUMMARY}

A cold-air cyclogenesis is studied using a potential vorticity (PV) inversion method. In this study, the method is coupled with the French spectral operational model ARPEGE which is initialized by four-dimensional variational reanalyses. Sensitivity studies are performed for Intensive Observation Period 18 (IOP18) (low 44, 19-24 February 1997) of the Fronts and Atlantic Storm-Track EXperiment (FASTEX). This event is one of the Type $\mathrm{C}$ cyclogeneses recently identified in the FASTEX dataset. The triggering role of a coherent tropopause disturbance on the cyclogenesis is discussed by comparing a reference forecast and a simulation in which the tropopause coherent structure is removed. Interactions between the atmospheric upper level and the cyclogenesis are found significant. A second important factor is the influence of the surface temperature. Evaluations of vertical motions for different surface temperature distributions show that the warmer the sea surface, the deeper the low. The location of the low with respect to the ice-shelf limit is also an important factor.

KEYWORDS: ARPEGE model Fronts and Atlantic Storm-Track EXperiment Surface temperature

\section{INTRODUCTION}

Potential vorticity $(\mathrm{PV})$ and its inversion are recognized as fundamental tools for investigating the cyclogenesis process. PV, as a conservative variable of adiabatic motions in inviscid flows, was first introduced by Rossby (1940) and was generalized by Ertel (1942). However, it was with the Hoskins et al. (1985) paper that PV began to be applied to a full range of atmospheric problems. Nielsen-Gammon (2001) examines the range of current applications of PV concepts in the atmospheric sciences. PV inversion dates back to Kleinschmidt $(1950 \mathrm{a}, \mathrm{b})$ but the widespread use of PV inversion as a diagnostic tool started with Hoskins et al. (1985) and was later employed by Davis and Emanuel (1991), Griffiths et al. (2000), Chaigne and Arbogast (2000) (hereafter CA2000) and others.

As recalled by Whitaker and Barcilon (1992), 'observations show that the initial development of surface cyclones in middle latitudes is usually preceded by the arrival of a pre-existing upper-level trough'. However, interaction between the upper-level trough and low-level cyclone is a concept introduced by Petterssen et al. (1955) and complemented by Petterssen and Smebye (1971). It is based on the fact that extratropical cyclogenesis involves vertical as well as lateral interactions. More recently, Chang (2000) showed that a surface cyclone can frequently be identified developing just to the east of the upper-level trough, suggesting that surface cyclogenesis is often caused by approaching an upper-level wave packet. Ayrault (1998) proposed a statistical classification of cyclogenesis which is broader than the Type A or Type B described by Petterssen and Smebye (1971). He suggested six scenarios, four of which imply an altitude precursor. On average, almost three cyclogeneses every winter month over the northern Atlantic involve an upper-level precursor. This figure corresponds to approximately half the total number of cyclogeneses. Finally, a recent statistical compilation of the Fronts and Atlantic Storm-Track Experiment (FASTEX) by Deveson

\footnotetext{
* Corresponding author: Laboratoire d'Aérologie, UMR CNRS/UPS 5560, Observatoire Midi-Pyrénées, 14 Av. Edouard Belin, 31400 Toulouse, France. e-mail: Dominique.Lambert@aero.obs-mip.fr
} 
et al. (2002) found a majority of Type A and Type B cyclones, but also identified three examples of a new Type $\mathrm{C}$ cyclogenesis associated with a pre-existing upper trough.

Another important aspect in cyclogenesis is the influence of the surface. It was first considered by Bergeron (1954) and has since been studied by many authors. For example, Emanuel (1994) shows that some maritime extratropical cyclones tap the thermodynamic non-equilibrium between the sea surface and the overlying atmosphere.

The PV perspective provides a basis for linking upper- and lower-tropospheric processes in the evolution of rapidly developing storms (Uccellini 1990). This paper is based on the use of the PV inversion tool coupled with a global model to perform sensitivity tests during a cold-air cyclogenesis above the east coast of Canada and south Greenland during the FASTEX. First, the interaction scheme between upper-level trough and surface cyclone is tested. Then, the sensitivity of the penetrating depth of the upperlevel forcing to the surface temperature is investigated.

The paper is structured as follows: in section 2 the situation under study and the method used are presented, in section 3 a first experiment is presented which addresses the triggering role of an upper-level PV coherent structure on the surface low development, and in section 4 further experiments are discussed to investigate the impact of surface temperature and boundary-layer stability on cyclogenesis.

\section{Methodology AND EXPERIMENTAL SITUATION}

\section{(a) The methodology}

The principle of the manipulation of initial conditions through quasi-geostrophic PV and the PV inversion tool are presented in CA2000. The method is coupled with the French spectral operational model ARPEGE* (see Courtier et al. (1991) for more details) with T95 spectral resolution (which corresponds to about two degrees in the North Atlantic) and 27 vertical levels. All plots presented here use this resolution. All the reanalyses used in the present study include FASTEX special data (soundings, aircraft and ship measurements, etc.) which have been added to the conventional dataset and assimilated with a four-dimensional variational (4D-Var) scheme (see Desroziers et al. $(1999,2003)$ for details).

In this paper, an experiment in which some PV is removed or modified is called a 'modified' experiment. The PV inversion tool is implemented using two different strategies. In the first strategy, two ARPEGE simulations of the same case study are compared. These two simulations are performed with identical model tuning except for the initial conditions. The initial conditions for the first (reference) simulation are the standard ARPEGE reanalyses. Initial conditions for the second simulation are obtained from a PV surgery methodology which follows CA2000. PV surgery is performed in three steps: first, the ARPEGE reanalyses are examined to locate interesting PV structures; second, these identified structures are removed; and finally, the PV inversion tool is used to retrieve modified velocity and temperature fields corresponding to the modified PV field.

While, in the above procedure, the field modification is performed at the initial time of the simulation on reanalysis fields, the second strategy is based on a forecasted field modification (by surgery). Furthermore, in the second strategy, the inversion tool is used as an 'attribution tool' (Thorpe 1997) to identify the velocity and temperature perturbations attributable to a specific PV structure. Attribution just involves an additional subtraction.

* Action de Recherche Petite Echelle et Grande Echelle. 
We proceed as follows: first, a PV field is computed from a model forecast; second, the PV field is examined to identify specific structures; third, a specific structure (the anomaly) is removed and the PV inversion is performed to retrieve the velocity and temperature fields. These fields are then subtracted from the velocity and temperature fields of the unmodified forecast, and these differences are interpreted as the velocity and temperature perturbations attributable to the structure removed.

The PV inversion tool is very useful, but we have to keep in mind that any PV inversion is subject to inherent ambiguities. First, the method of subtracting the without-anomaly fields from the total fields is a common approach, but is not unique. Our inversion is linear, unlike the approach of Davis and Emanuel (1991), for instance. Second, when the PV structure of interest is 'removed', it is replaced by some other PV structure referred to as 'background'. In this study, the background is the first seven wave numbers of the analysis before modification. This field could be called the planetary component of the PV. The choice of boundary is also subjective; one may choose either a Dirichlet-type boundary condition (wind, geopotential, vorticity) or a Neumann one (temperature). In the present experiment, we choose to take a homogeneous temperature for the boundary condition, i.e. we specify an artificial surface temperature.

\section{(b) The experiment}

The FASTEX (Joly et al. 1999) was an international field project which took place over the North Atlantic in January and February 1997 to make detailed observations of extratropical cyclones reaching the west coast of Europe. FASTEX intensive observation period 18 (IOP 18; low 44, 19-24 February 1997) was devoted to the study of a coldair cyclogenesis over the Labrador Sea that involved a major tropopause disturbance (Joly et al. 1999; Baehr et al. 1999; Fourrié et al. 2000; Donnadille et al. 2001a,b; Deveson et al. 2002). Donnadille et al. (2001a) have documented the life cycle of a tropopause fold associated with the development of low 44. The role of a coherent tropopause disturbance (CTD) in this tropopause fold has been studied. Deveson et al. (2002) have examined the later explosive development of this low, and classified it as a Type $\mathrm{C}$ cyclone. According to these authors, Type $\mathrm{C}$ cyclones form at high latitudes, when a large upper-level trough moves over the ocean. They have a similar structure to polar lows. In this paper, we are interested only in the ice-ocean transition of low 44 at the very beginning of IOP 18 .

Figure 1 shows $1000 \mathrm{hPa}$ geopotential reanalyses at 0000 UTC on 19 February, 0000 and 1800 UTC on 21 February, and 1200 UTC on 22 February over North America and the North Atlantic. At 0000 UTC on 19 February, low 44 had not yet formed. A surface low was forming north-west of Hudson Bay and a deep surface trough reached the west coast of the United States. These two lows propagated eastwards, the first one extending south-eastwards. At 0000 UTC on 21 February, they formed a single geopotential minimum $(-20 \mathrm{~m})$ located near the east coast of Hudson Bay; this corresponds to the IOP 18 low. From 0000 to 1200 UTC on 21 February (not shown), the minimum on the $1000 \mathrm{hPa}$ geopotential surface propagated eastwards showing no significant deepening. At 1800 UTC on 21 February, low 44 was $-60 \mathrm{~m}$ deep and located at approximately $57^{\circ} \mathrm{N}, 56^{\circ} \mathrm{W}$. The deepening of the low occurred when the low crossed the edge of the ice shelf. From that time onwards, the surface low propagated eastwards and deepened further. It reached $-100 \mathrm{~m}$, south of Greenland, at 1200 UTC on 22 February.

Figure 2 presents the $850 \mathrm{hPa}$ geostrophic relative vorticity at $1200 \mathrm{UTC}$ on 22 February computed from reanalyses. As explained by Ayrault (1998), with this parameter, large scales are automatically filtered because of the near-Laplacian behaviour 


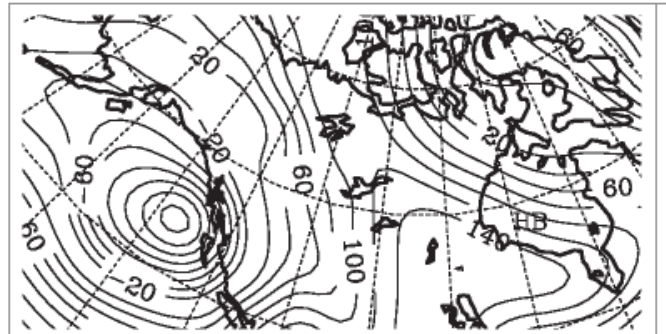

(a) 19 February 0000 UTC

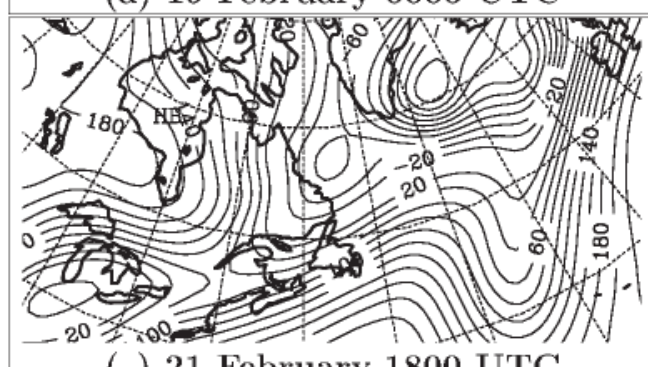

( ) 21 February 1800 UTC

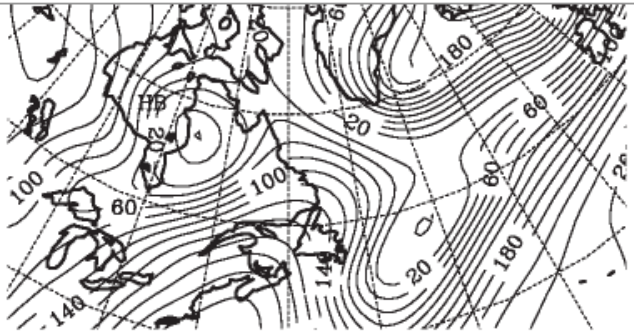

(b) 21 February 0000 UTC

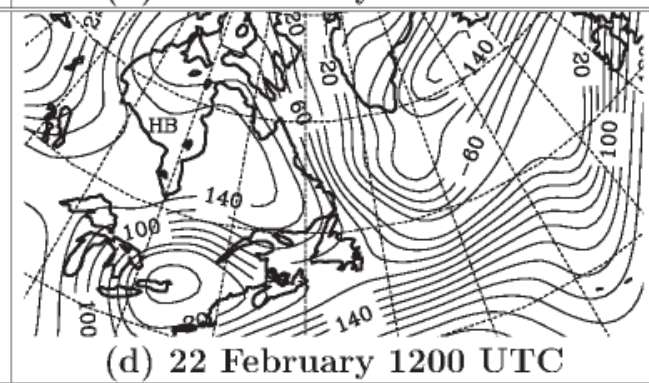

Figure 1. $1000 \mathrm{hPa}$ geopotential reanalysis at (a) 0000 UTC on 19 February, (b) 0000 UTC on 21 February, (c) 1800 UTC on 21 February, and (d) 1200 UTC on 22 February. The contour interval is $20 \mathrm{~m}$, with 0 m omitted. Negative values correspond to low surface pressure $(<1000 \mathrm{hPa})$ for which the $1000 \mathrm{hPa}$ level is virtually below ground. 'HB' indicates Hudson Bay.

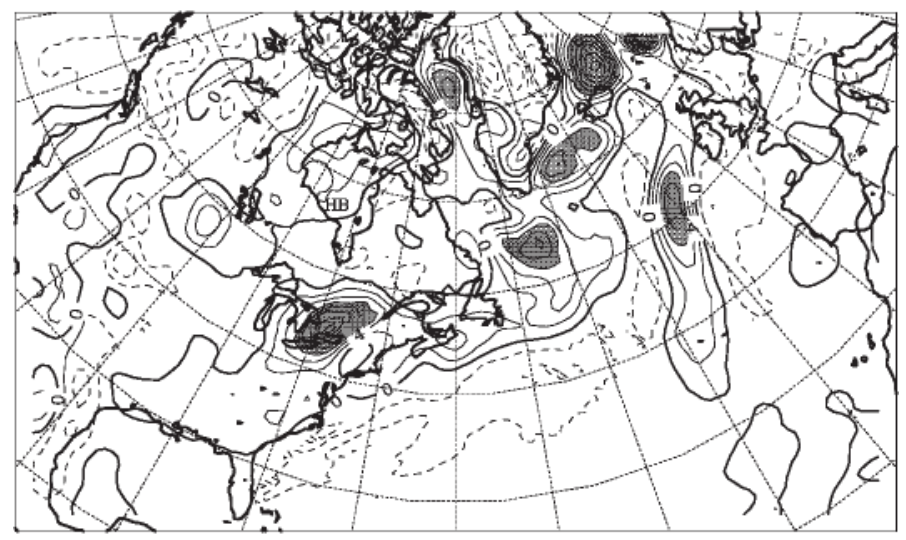

Figure 2. $850 \mathrm{hPa}$ geostrophic relative vorticity at 1200 UTC on 22 February, with bold line denoting zero, contour interval $2 \times 10^{-5} \mathrm{~s}^{-1}$, solid (dashed) lines showing positive (negative) values, and with shading for values greater than $6 \times 10^{-5} \mathrm{~s}^{-1}$. 'HB' indicates Hudson Bay.

of the geopotential field. On Fig. 2, IOP 18 is characterized by a maximum geostrophic relative vorticity of $10^{-4} \mathrm{~s}^{-1}$ to the south of Greenland. This maximum agrees with the position of the low on Fig. 1(d). It will be shown that the $850 \mathrm{hPa}$ geostrophic relative vorticity is less variable across the various experiments than the $1000 \mathrm{hPa}$ geopotential height. Therefore, the geopotential evolution will be used as a reference for the validation of our forecasts presented below. 
TABLE 1. LIST OF SIMULATIONS, WHICH ARE ALL 36-HOUR FORECASTS FROM 0000 UTC ON 21 FEBRUARY. 'REF' DENOTES THE REFERENCE RUN.

\begin{tabular}{cccc}
\hline $\begin{array}{c}\text { Experiment } \\
\text { number }\end{array}$ & $\begin{array}{c}\text { CTD removal } \\
\text { at initial time }\end{array}$ & $\begin{array}{c}\text { Sea surface } \\
\text { temperature }(\mathrm{K})\end{array}$ & $\begin{array}{c}\text { Location of sea surface } \\
\text { temperature modification }\end{array}$ \\
\hline $0_{\mathrm{a}}$ & no & $\mathrm{REF}$ & $\mathrm{REF}$ \\
$0_{\mathrm{b}}$ & yes & $\mathrm{REF}$ & $\mathrm{REF}$ \\
1 & no & 238 & north of $45^{\circ} \mathrm{N}$ \\
2 & no & 256 & north of $45^{\circ} \mathrm{N}$ \\
3 & no & 276 & north of $45^{\circ} \mathrm{N}$ \\
4 & no & $238 / \mathrm{REF}$ & north of $45^{\circ} \mathrm{N}$, west of $55^{\circ} \mathrm{W}$ \\
5 & no & $238 / \mathrm{REF}$ & north of $45^{\circ} \mathrm{N}$, west of $50^{\circ} \mathrm{W}$ \\
6 & no & $238 / \mathrm{REF}$ & north of $45^{\circ} \mathrm{N}$, west of $45^{\circ} \mathrm{W}$ \\
\hline
\end{tabular}

\section{TRIGGERING ROLE OF THE COHERENT TROPOPAUSE DISTURBANCE ON THE CYCLOGENESIS}

A first experiment was designed to demonstrate the triggering role of the CTD on the surface low development by comparing a reference forecast (experiment $0_{\mathrm{a}}$ in Table 1) with a forecast in which the CTD structure had been removed at the initial time (experiment $0_{\mathrm{b}}$ in Table 1). Figures 3(a) and (c) present vertical and isobaric sections, respectively, of the CTD at 0000 UTC on 21 February. This date was chosen because the IOP 18 surface low and the CTD were well defined, though the surface low was still in a non-deepening phase (see Fig. 1). The maximum value of $\mathrm{PV}$ at $500 \mathrm{hPa}$ is located at approximately $58^{\circ} \mathrm{N}, 83^{\circ} \mathrm{W}$, and the IOP 18 low (see Fig. 1(b)) is just east of the $\mathrm{CTD}$, at approximately $57^{\circ} \mathrm{N}, 76^{\circ} \mathrm{W}$. Figure $3(\mathrm{e})$ shows the 36 -hour reference forecast for the $1000 \mathrm{hPa}$ geopotential field valid at 1200 UTC on 22 February. This forecast fits the 4D-Var ARPEGE reanalysis well (Fig. 1(d)); the low 44 is well developed south of Greenland at $-80 \mathrm{~m}$.

Figures 3(b) and (d) show the same fields, but for the experiment in which the CTD had been removed. However, some modifications of the PV can be observed away from the immediate vicinity of the CTD. For example, towards the left of the vertical sections, the PV contours at $200 \mathrm{hPa}$ appear almost horizontal in Fig. 3(b), but not quite so in Fig. 3(a). Also, there are some small differences in PV between 400 and $500 \mathrm{hPa}$ on the extreme left of the figures. This highlights the non-local character of the PV inversion method mentioned in section 2(a). These differences are minor, so the removal of the CTD is the main characteristic of the comparison of Figs. 3(a) and (c) with Figs. 3(b) and (d). This corresponds to the objective of the study. In the PV-modified forecast, there is no surface low south of Greenland (Fig. 3(f)). However, the Icelandic trough is still present and even stronger. So, we can conclude that the CTD was essential for the cyclogenesis of IOP 18.

\section{IS THE PENETRATING DEPTH OF UPPER-LEVEL FORCING SENSITIVE TO SURFACE TEMPERATURE?}

We have shown the triggering role of the CTD on cyclogenesis. The influence of the surface temperature will now be investigated. Figure 4 presents the ARPEGE surface temperature field at 0000 UTC on 21 February 1997. A clear-cut gradient located off the east coast of Canada corresponds to the limit between ice shelf and open ocean visualized on the ERS-2 satellite ice-mask image (Fig. 5)*.

\footnotetext{
* Although there is a difference of about three days in the timings of Figs. 4 and 5, we can reasonably suppose little movement of the ice shelf during this time.
} 


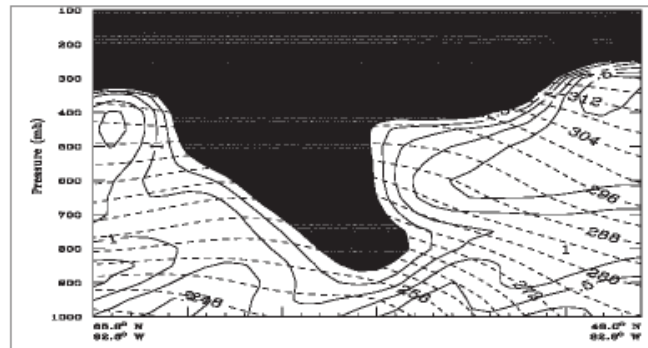

(a) 21 February 0000 UTC

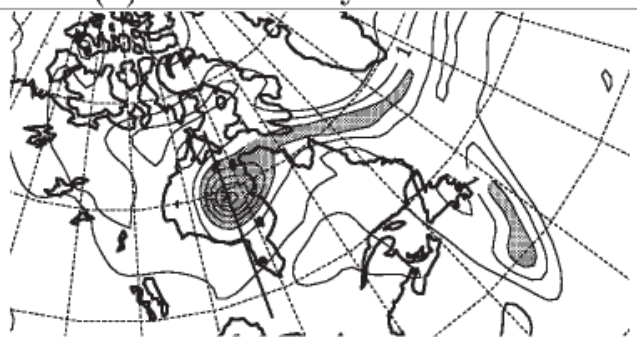

( ) 21 February 0000 UTC

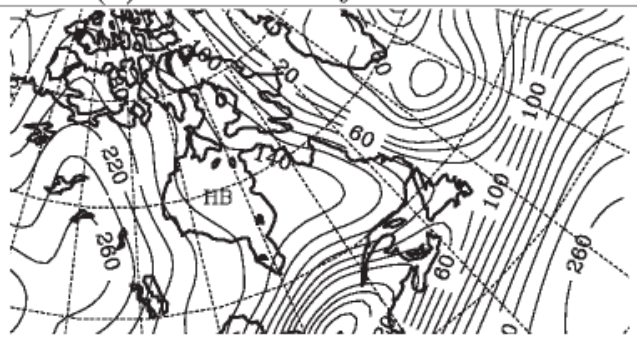

(e) 22 February 1200 UTC

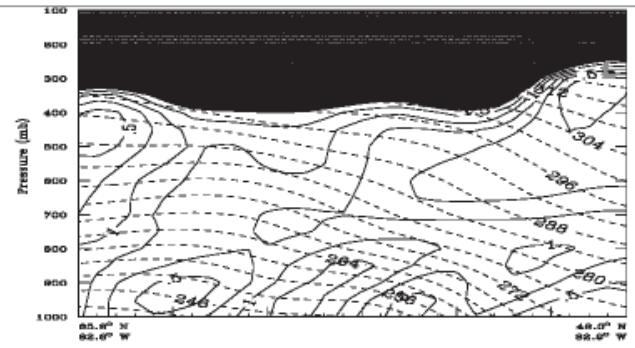

(b) 21 February 0000 UTC

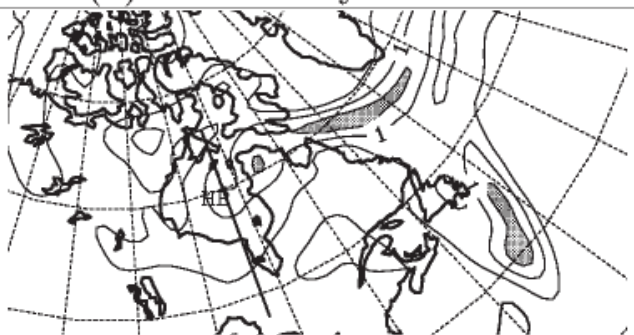

(d) 21 February 0000 UTC

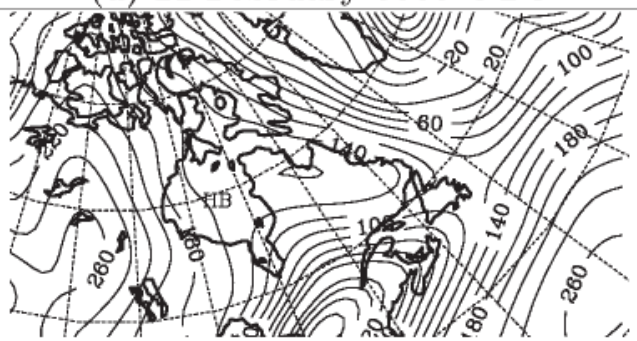

(f) 22 February 1200 UTC

Figure 3. (a) North-south section through Hudson Bay of potential vorticity (PV, solid lines with interval 0.25 pvu up to $7.5 \mathrm{pvu}$, shaded above $1.5 \mathrm{pvu})\left(1 \mathrm{pvu}=10^{-6} \mathrm{~K} \mathrm{~m}^{2} \mathrm{~s}^{-1} \mathrm{~kg}^{-1}\right)$, and potential temperature (dashed lines with interval $4 \mathrm{~K}$ up to $340 \mathrm{~K}$ ) at 0000 UTC on 21 February 1997. (b) is as (a), but with the coherent tropopause disturbance (CTD) removed. (c) and (d) show $500 \mathrm{hPa} \mathrm{PV}$ corresponding to (a) and (b) respectively, with contours at intervals of $0.5 \mathrm{pvu}$ and shaded above $1.5 \mathrm{pvu}$; line of cross-section (a) and (b) is also shown. (e) shows 36-hour reference forecast of $1000 \mathrm{hPa}$ geopotential field (every $20 \mathrm{~m}$, contour $0 \mathrm{~m}$ not drawn) valid at 1200 UTC on 22 February, and (f) shows the same but for the experiment in which the CTD was removed.

'HB' indicates Hudson Bay.

In the interpretation of Fig. 1(c), we mentioned that the IOP 18 surface low deepened when it crossed the edge of the ice shelf (1800 UTC on 21 February). This contrasts with the near-absence of surface low deepening during the earlier phase, when the surface low was located inland or over the ice shelf. As recalled in the introduction, the sensitivity of the dynamics of extratropical cyclones to the surface temperature is still a controversial question. In this section, we investigate the role of surface temperature and boundary-layer stability at the limit between ice shelf and open ocean. In other words, can the ice-ocean transition be interpreted as a surface precursor as suggested by Neiman and Shapiro (1993) and Emanuel (1994)? A series of simulations with sea surface temperature (SST) modifications at initial time (but without modification of surface roughness) were performed (Table 1 ). Experiment $0_{a}$ is the reference run with the ARPEGE analysis of surface temperature. Experiment 1 was run with a modified SST, prescribed as a uniform value of $238 \mathrm{~K}$ north of $45^{\circ} \mathrm{N}$. This value of $238 \mathrm{~K}$ roughly 


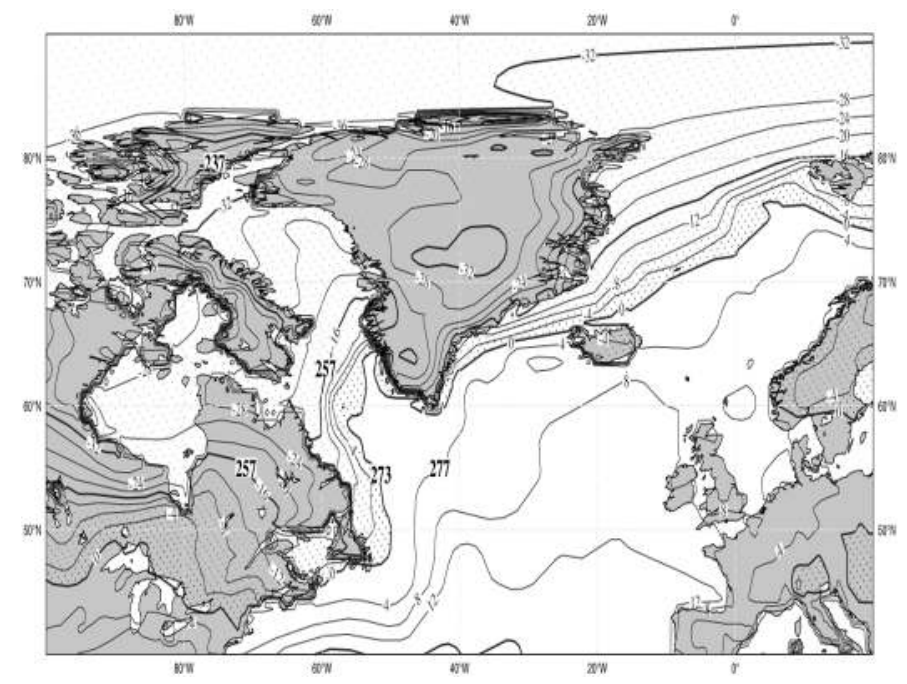

Figure 4. Surface temperature field $\left({ }^{\circ} \mathrm{C}\right.$ and $\mathrm{K}$ in bold) from ARPEGE at $0000 \mathrm{UTC}$ on 21 February 1997 (contour interval $4 \mathrm{~K}$, dotted for temperatures below $273 \mathrm{~K}$ ).

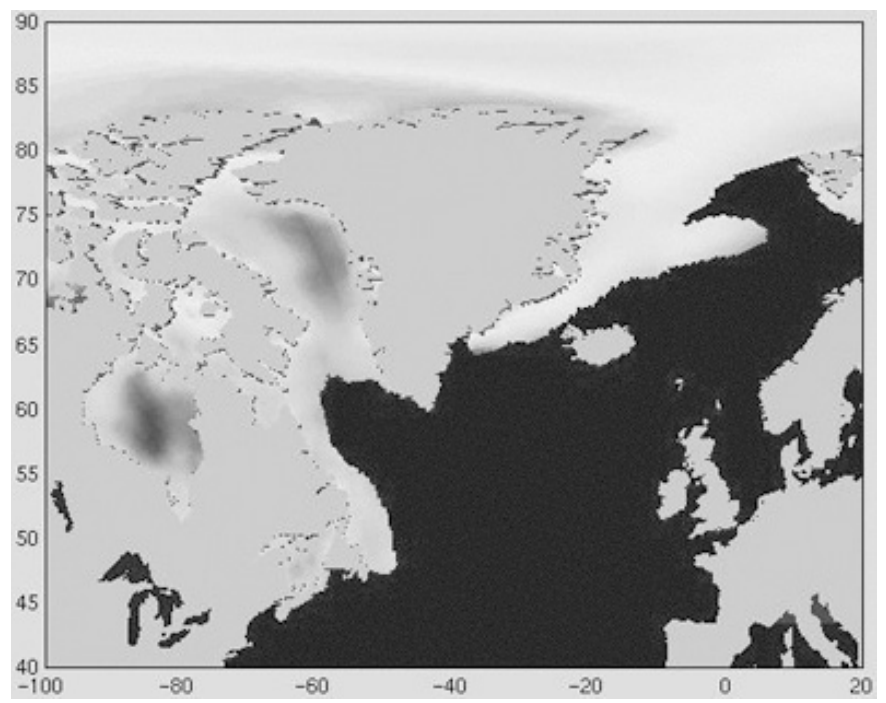

Figure 5. Ice mask from ERS-2 at 0200 UTC on 24 February 1997 (courtesy of IFREMER/Laboratoire d'Océanographie Spatiale/Cersat). Ice areas are discriminated from the consistency of backscatter data gathered from the microwave scatterometer.

corresponds to the observed temperature of the Arctic ice shelf north of Canada (Fig. 4). Experiments 2 to 6 will be discussed below. For the present discussion of the surface flux contribution to the low 44 cyclogenesis, we compare the 36-hour model forecast from 0000 UTC on 21 February, in the different simulations in Table 1, and attention is focused on the area where the actual low 44 development occurred (approximately $\left.55^{\circ} \mathrm{N}, 43^{\circ} \mathrm{W}\right)$. Using the methodology presented in section 2(a), the PV-inversion is used here as an 'attribution' tool (Thorpe 1997) to interpret the difference at 1200 UTC 
(a)

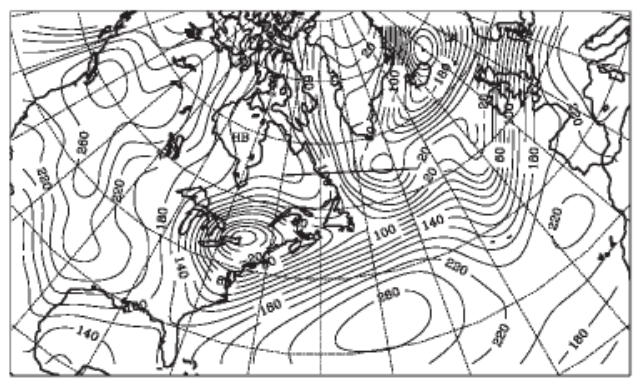

(c)

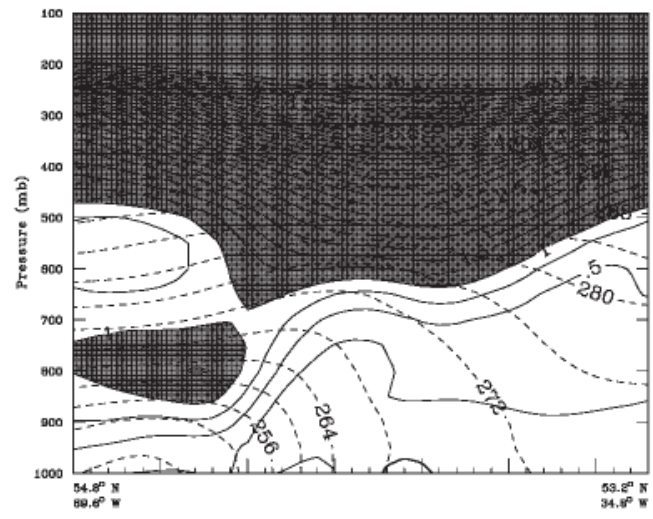

(b)

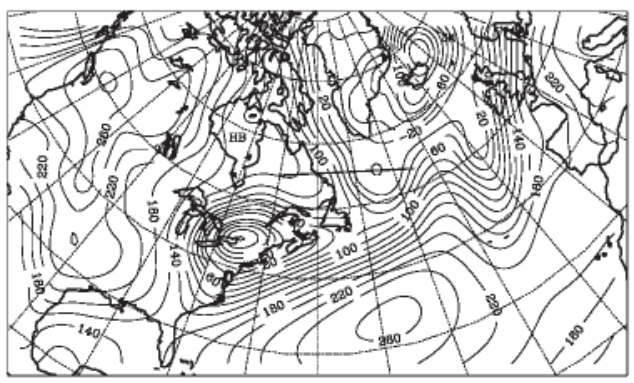

(d)

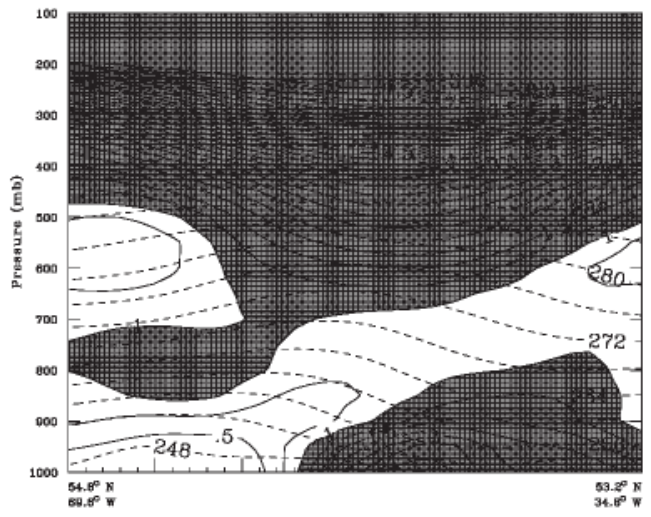

Figure 6. (a) 36-hour forecast of $1000 \mathrm{hPa}$ geopotential height (contour interval $20 \mathrm{~m}$, zero not drawn) valid at 1200 UTC on 22 February 1997 from the reference surface temperature experiment $0_{a}$ in Table 1 . (b) is as (a), but from experiment 1 in Table 1, with the sea surface temperature set to $238 \mathrm{~K}$ north of $45^{\circ} \mathrm{N}$. (c) and (d) are vertical sections of potential vorticity (solid lines with interval 0.25 pvu up to $7.5 \mathrm{pvu}$, shaded above 1 pvu) and potential temperature (dashed lines with interval $4 \mathrm{~K}$, up to $340 \mathrm{~K}$ ), along the east-west lines shown on (a) and (b).

on 22 February resulting from the real and modified surface temperature fields. Figures 6 and 7 compare experiments $0_{\mathrm{a}}$ and 1 to start the discussion.

Figure 6 presents the sensitivity of the $1000 \mathrm{hPa}$ geopotential evolution and illustrates the PV and potential temperature evolution along a vertical cross-section. As noted in the previous section, for the reference run (experiment $0_{\mathrm{a}}$ ), a good agreement is found with the ARPEGE reanalysis for both the location (south of Greenland) and deepening (20 m underestimation) of low 44.

Comparing Figs. 6(a) and 6(b), we can assess the sensitivity of the $1000 \mathrm{hPa}$ geopotential evolution to the SST. When the SST is set to $238 \mathrm{~K}$ north of $45^{\circ} \mathrm{N}$ (experiment 1), the surface low is still present, has nearly the same location, but is less intense (-20 m, Fig. 6(b) and Table 2). Figures 6(c) and (d) show vertical sections of PV and potential temperature for 1200 UTC on 22 February from $55^{\circ} \mathrm{N}, 70^{\circ} \mathrm{W}$ to $53^{\circ} \mathrm{N}, 35^{\circ} \mathrm{W}$, i.e. from Canada to the open sea (see location on Figs. 6(a) or (b)). These two sections are very similar above $700 \mathrm{hPa}$ and show a well-defined clear-cut upper-level PV feature located in the middle of the sections (local maximum of PV and local minimum in potential temperature), which corresponds to the CTD.

The main difference between these two sections occurs in the lower atmosphere and near the surface. To characterize the lower part of the atmosphere, we estimated the Brunt-Väisälä frequency, $N_{900}$, in the boundary layer at $900 \mathrm{hPa}$ over two areas, 
(a)

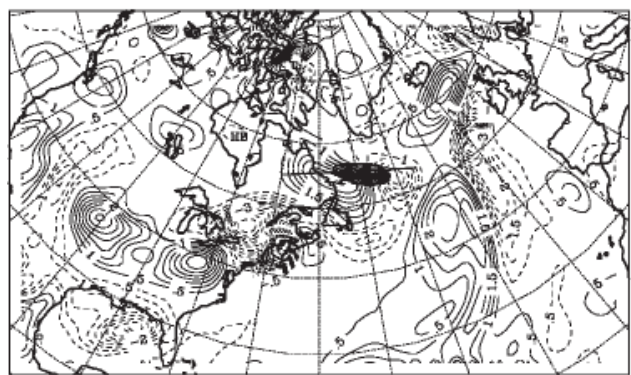

(c)

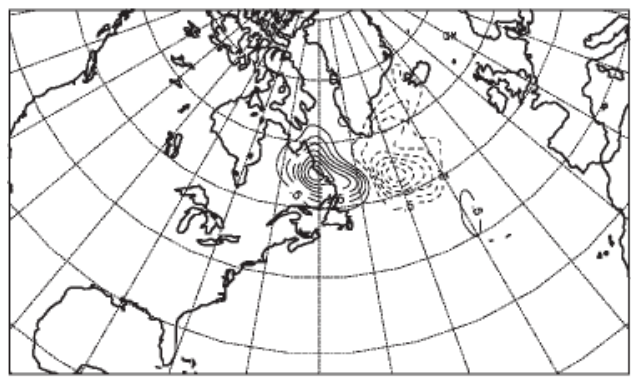

(b)

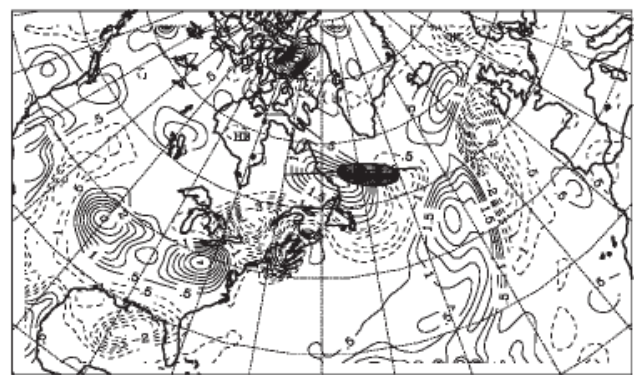

(d)

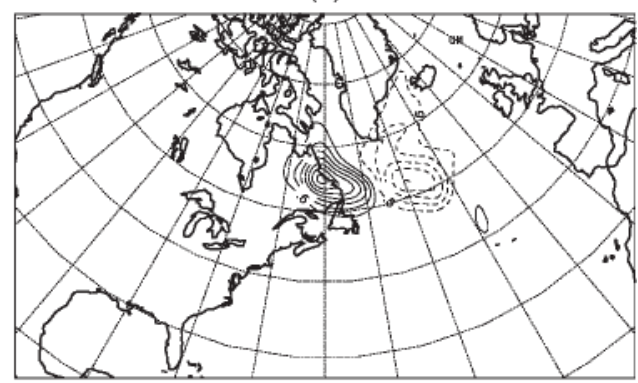

Figure 7. 36-hour forecast valid 1200 UTC on 22 February. (a) and (b) are as Figs. 6(a) and (b), but show 500 hPa potential vorticity (bold line shaded above $2 \mathrm{pvu}$ ) and vertical velocity (upward motion dashed and downward motion solid contours, with interval $0.5 \times 10^{-1} \mathrm{~Pa} \mathrm{~s}^{-1}$ ). The east-west line corresponds to the location of the vertical cross section in Fig. 8. (c) and (d) are the difference between the reference and the 'modified' $500 \mathrm{hPa}$ vertical velocity forecasts. (a) and (c) are for the reference surface temperature (experiment $0_{\mathrm{a}}$ in Table 1), and (b) and (d) are for the SST set to $238 \mathrm{~K}$ north of $45^{\circ} \mathrm{N}$ (experiment 1 in Table 1 ).

TABLE 2. Simulated VALUES OF IOP 18 GEOPOTENTIAL HEIGHT, GEOSTROPHIC RELATIVE VORTICITY AND GEOPOTENTIAL HEIGHT OF THE ICELANDIC LOW

\begin{tabular}{cccc}
\hline $\begin{array}{c}\text { Experiment } \\
\text { Number } \\
\text { (see Table } 1\end{array}$ & $\begin{array}{c}1000 \mathrm{hPa} \\
\text { geopotential height } \\
(\mathrm{m})\end{array}$ & $\begin{array}{c}850 \mathrm{hPa} \text { geostrophic } \\
\text { relative vorticity } \\
\left(\times 10^{-5} \mathrm{~s}^{-1}\right)\end{array}$ & $\begin{array}{c}1000 \mathrm{hPa} \\
\text { geopotential height } \\
(\mathrm{m})\end{array}$ \\
\hline $0_{\mathrm{a}}$ & near $55^{\circ} \mathrm{N}, 44^{\circ} \mathrm{W}$ & near $55^{\circ} \mathrm{N}, 44^{\circ} \mathrm{W}$ & $\begin{array}{c}\text { of the Icelandic low } \\
1\end{array}$ \\
2 & -80 & 10 (weak min.) & -280 \\
3 & -40 & 8 & -170 \\
4 & -100 & 8 & -210 \\
5 & -80 & 10 & -270 \\
6 & $\simeq-60$ (no min.) & 8 & -280 \\
\hline
\end{tabular}

to the left $\left(64^{\circ} \mathrm{W}\right)$ and right $\left(42^{\circ} \mathrm{W}\right)$ of the vertical section for the reference run and for the run with the $238 \mathrm{~K} \mathrm{SST}$ north of $45^{\circ} \mathrm{N}$. In the west of the reference section (Fig. 6(c)), there is a stable boundary layer $\left(N_{900} \simeq 1.5 \times 10^{-2} \mathrm{~Hz}\right)$, while to the east the boundary layer is much less stable, i.e. nearly neutral $\left(N_{900} \simeq 7.3 \times 10^{-3} \mathrm{~Hz}\right)$. At approximately $55^{\circ} \mathrm{W}$, in the middle of the vertical section, there is the transition between the ice shelf and the warmer open ocean (see Fig. 4). A very different picture is found in Fig. 6(d), which corresponds to experiment 1 (Table 1), i.e. to a uniformly very cold North Atlantic Ocean. Near the surface, isentropes are quasi-horizontal throughout the section, showing that the boundary layer is stable everywhere. On Fig. 6(d), the 
TABLE 3. MAXIMUM OF $500 \mathrm{hPa}$ VERTICAL VElocity ASSOCIATED WITH THE LOCATION OF THE CTD IN EXPERIMENTS 0 a AND 1

\begin{tabular}{lcc}
\hline & $\begin{array}{c}\text { Reference forecast } \\
\left(\text { experiment } 0_{\mathrm{a}}\right)\end{array}$ & $\begin{array}{c}\text { Forecast with } 238 \mathrm{~K} \text { north of } 45^{\circ} \mathrm{N} \\
(\text { experiment } 1)\end{array}$ \\
\hline with CTD & $W 1_{\text {up }}=3$ & $W 2_{\text {up }}=2$ \\
$W 1_{\text {down }}=3.5$ & $W 2_{\text {down }}=3.5$ \\
without CTD & $W 3 \simeq 0$ & $W 4 \simeq 0$ \\
\hline Units: $\times 10^{-1} \mathrm{~Pa} \mathrm{~s}^{-1}$.
\end{tabular}

eastern part of the boundary layer is even more stable $\left(N_{900} \simeq 1.9 \times 10^{-2} \mathrm{~Hz}\right)$ than the western part $\left(N_{900} \simeq 1.7 \times 10^{-2} \mathrm{~Hz}\right)$ because the atmospheric cooling resulting from the cold surface temperature is restricted to the very lowest model levels (even after 36 hours of running).

High PV values in the eastern marine boundary layer confirm the above interpretation. As atmospheric lower levels are homogeneously cool in experiment 1 and the atmospheric temperature aloft is higher over the ocean, the boundary-layer mixing is somewhat weaker over the ocean than over the land, leading to a slightly more stable oceanic boundary layer on the eastern part of the vertical section (Fig. 6(d)). Conversely, the opposite situation is found in experiment $0_{a}$ (Fig. 6(c)), where the ocean off the Canadian coast is warmer than the nearby continent. As a cold and very stable boundary layer is a potential inhibitor of cyclogenesis (through inhibition by vertical stretching and thermal advection, Neiman and Shapiro (1993)), the results of Fig. 6 suggest that the cyclogenetic action of the upper-level CTD is opposed by the very stable marine boundary layer in experiment 1 (cold ocean) and conversely favoured by the less stable boundary layer in experiment $0_{\mathrm{a}}$ (reference ocean).

Associating surface and upper-level modifications allows a factor-separating experiment to be carried out (Alpert et al. 1995). In this section, vertical velocity fields will be computed for both experiment $0_{\mathrm{a}}$ and experiment 1 from ARPEGE fields either including CTD or excluding CTD (with the PV inversion tool). The objective will be to examine a possible contribution of the surface processes to the vertical motions associated with the CTD. Figure 7 presents a diagnostic computation of vertical velocity fields performed using the Alternative Balance $(\mathrm{AB})$ omega equation (Davies-Jones 1991; Mallet et al. 1999; Donnadille et al. 2001b). Based on the geostrophic momentum approximation, the $\mathrm{AB}$ omega equation keeps the formalism of the quasi-geostrophic omega equation by approximating the horizontal and vertical derivatives of the wind by those of the non-divergent and geostrophic winds, respectively. The linearity of the omega equation allows vertical velocity shown on Fig. 7 to be derived.

We begin with vertical velocities computed from experiment $0_{\text {a }}$ (reference) without any manipulation of the upper-level flow in the CTD area. Let $\mathrm{W} 1$ be the vertical velocity field obtained in this case (see Table 3). In this case, the PV maximum value (which corresponds to the CTD) is located upstream of low 44. The horizontal distance between the upper-level trough (whose location corresponds to the centre of the maximum PV value on a $500 \mathrm{hPa}$ map plotted with more contours (not shown)) and the low-level cyclone for experiment $0_{\mathrm{a}}$ is approximately $350 \mathrm{~km}$ at $1200 \mathrm{UTC}$ on 22 February. This is in agreement with the Type $C$ cyclogenesis tilting proposed by Deveson et al. (2002). On their Figs. 7 and 8, these authors show that Type B cyclogenesis is characterized by high values of tilting (about $600 \mathrm{~km}$ decreasing with time), whereas Type $\mathrm{C}$ cyclogenesis is characterized by low values of tilting (about $200 \mathrm{~km}$ increasing with time). 
(a)

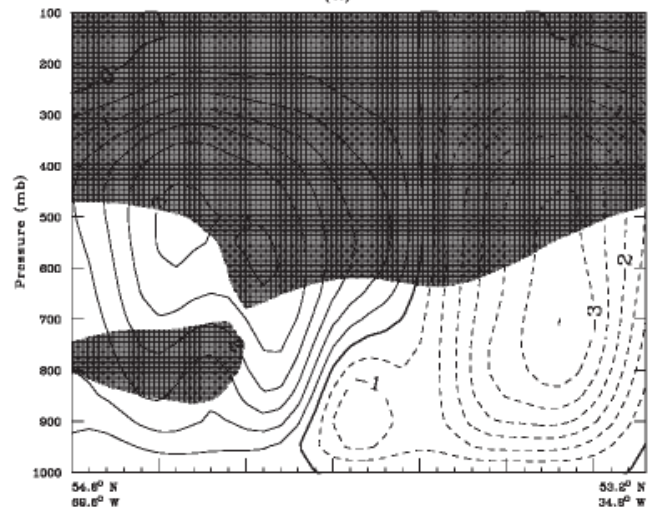

(b)

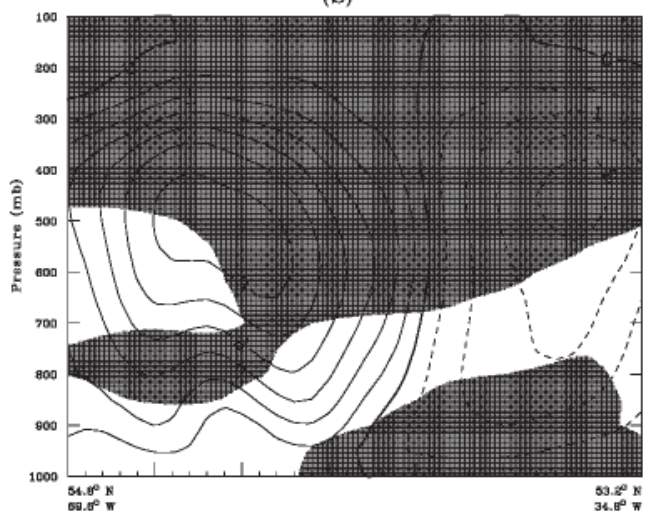

Figure 8. Cross-section of vertical velocity $\left(\times 10^{-1} \mathrm{~Pa} \mathrm{~s}^{-1}\right)$ (upward motion dashed and downward motion solid) and PV shaded above 1 pvu for 36-hour forecast valid at 1200 UTC on 22 February: (a) uses the reference surface temperature (experiment $0_{\mathrm{a}}$ in Table 1) and (b) sets the SST to $238 \mathrm{~K}$ north of $45^{\circ} \mathrm{N}$ (experiment 1 in Table 1).

Associated with this upper-level PV coherent structure, there is a distinct dipole of vertical velocity with upward velocity downstream of the CTD and downward velocity upstream. On Fig. 7(a) (experiment $0_{a}$ with reference surface temperature in Table 1), the CTD is centred approximately at $55^{\circ} \mathrm{N}, 47^{\circ} \mathrm{W}$. This upper-level organization is also apparent with the SST set to $238 \mathrm{~K}$ north of $45^{\circ} \mathrm{N}$ (Fig. 7(b)), with the CTD again centred at $55^{\circ} \mathrm{N}, 47^{\circ} \mathrm{W}$. Maximum values of $500 \mathrm{hPa}$ upward and downward velocities for both experiments are reported in Table 3. Vertical sections of the vertical velocity from $55^{\circ} \mathrm{N}, 70^{\circ} \mathrm{W}$ to $53^{\circ} \mathrm{N}, 35^{\circ} \mathrm{W}$ are presented in Fig. 8 for experiments $0_{a}$ and 1 . The dipole associated with the CTD appears clearly.

Downward motion organization west of the CTD is very similar in the two experiments (experiment $0 \mathrm{a}$ and 1) with a maximum value near $500 \mathrm{hPa}$, but upward motions east of the CTD are very different in the two experiments. For experiment $0_{a}$, upward vertical velocities are higher (in absolute terms) than for experiment 1 . Moreover, maximum ascent is located near $700 \mathrm{hPa}$ and reaches $-3.5 \times 10^{-1} \mathrm{~Pa} \mathrm{~s}^{-1}$ for experiment $0_{\mathrm{a}}$, whereas the weak maximum ascent for experiment $1\left(-2 \times 10^{-1} \mathrm{~Pa} \mathrm{~s}^{-1}\right)$ is located near $500 \mathrm{hPa}$.

We now consider the same AB calculations performed at 1200 UTC on 22 February from forecast ARPEGE fields modified to remove the CTD (with the PV inversion tool as explained in section 2(a)). W4, in Table 3, corresponds to the cold surface case (experiment 1 ) with CTD removed. $W 3$, in Table 3 , was obtained by the same procedure applied to the realistic ocean case (36-hour forecast corresponding to experiment $0_{\mathrm{a}}$ ). Neither $W 4$ nor $W 3$ displayed any significant vertical motion off the southern tip of Greenland (not shown). To highlight the vertical velocity cell associated with the CTD, the difference between the simulations with and without CTD for a given surface temperature is presented: Fig. 7(c) for the reference case (experiment $0_{a}$ ) and Fig. 7(d) for the cold ocean case (experiment 1). We notice that the subsidence patterns of $W 1-W 3$ and $W 2-W 4$ upstream of the CTD are almost identical and correspond to the adiabatic part of the vertical circulation, whereas the upward (negative) difference patterns are weaker in experiment 1 (Fig. 7(d)) than in experiment $0_{\text {a }}$ (Fig. 7(c)). Further, it is interesting to consider how the CTD-associated vertical circulation varies as a function of the oceanic surface temperature by examining the difference between 


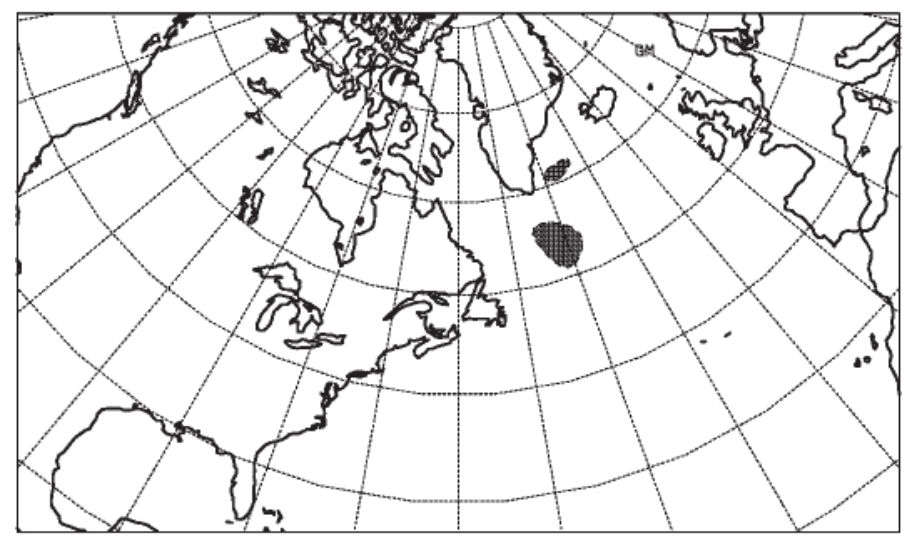

Figure 9. Difference in vertical velocity $\left(0.5 \times 10^{-1} \mathrm{~Pa} \mathrm{~s}^{-1}\right)$ at $500 \mathrm{hPa}$ : Fig. 7(c) minus Fig. 7(d). GM marks the Greenwich meridian.

Figs. 7(c) and (d), i.e. contours of $W 1-W 3-W 2+W 4$, which are shown in Fig. 9. We focus only on contours downstream of the CTD near $54^{\circ} \mathrm{N}, 42^{\circ} \mathrm{W}$, where low 44 is deepening (Fig. 6(a)). The main ascending vertical velocity patterns in Fig. 9 are located near the low 44 centre, and further south-east over the developing surface cold front. This distribution of the vertical ascent differences suggests that the cyclogenetic action of the upper-level CTD forcing is more favourable with the warmer surface environment.

Finally, five other modification experiments were done to examine whether the extent and geographical location of the surface temperature modifications were relevant factors in the low 44 evolution (Tables 1 and 2). Figure 10 presents a series of 36-hour $1000 \mathrm{hPa}$ geopotential forecasts from 0000 UTC on 21 February in which the surface temperatures have been modified as explained in Table 1. As an example, Fig. 11 presents the modified surface temperature field at 0000 UTC on 21 February in experiment 4 . It is worth noting that the surface low is present in every case, and is always located south of Greenland. For experiments 1, 2 and 3, where the SST is uniformly modified north of $45^{\circ} \mathrm{N}$, we find that the warmer the surface temperature, the deeper the cyclogenesis near the tip of Greenland. For experiments 4, 5 and 6, we can see that the surface low lies somewhat further to the east as the line of modification moves east. This interval can be explained by the retarded deepening of the low caused by weak simulated ice-shelf surface influence, when extending towards the east. For experiment 4 , where the Atlantic is cold west of $55^{\circ} \mathrm{W}$ and north of $45^{\circ} \mathrm{N}$, the $1000 \mathrm{hPa}$ geopotential minimum (Fig. 10(d)) is $-80 \mathrm{~m}$, as in the reference experiment (Table 2). However, the spatial extent of the geopotential minimum is smaller in experiment 4 than in the reference forecast (Fig. 6(a)). This small difference between reference and experiment 4 can be attributed to the location of the simulated ice limit.

As we can see on Figs. 4 and 5, around 22 February the ice shelf extended up to $55^{\circ} \mathrm{W}$ at $57^{\circ} \mathrm{N}$ off Labrador along the track of the low. Therefore, in this region, the real and the imposed (experiment 4) maximum surface temperature gradient are at the same location. They differ only in intensity, the prescribed ice-shelf temperature being lower off the Canadian coast west of the ice shelf-ocean limit. For example, off Nain, at approximately $56^{\circ} \mathrm{N}, 60^{\circ} \mathrm{W}$, the reference ARPEGE surface temperature is about $258 \mathrm{~K}$ while it is $238 \mathrm{~K}$ in experiment 4 . While above the continent the surface temperature is the same for each experiment, the $238 \mathrm{~K} \mathrm{SST}$ of experiment 4 tends 

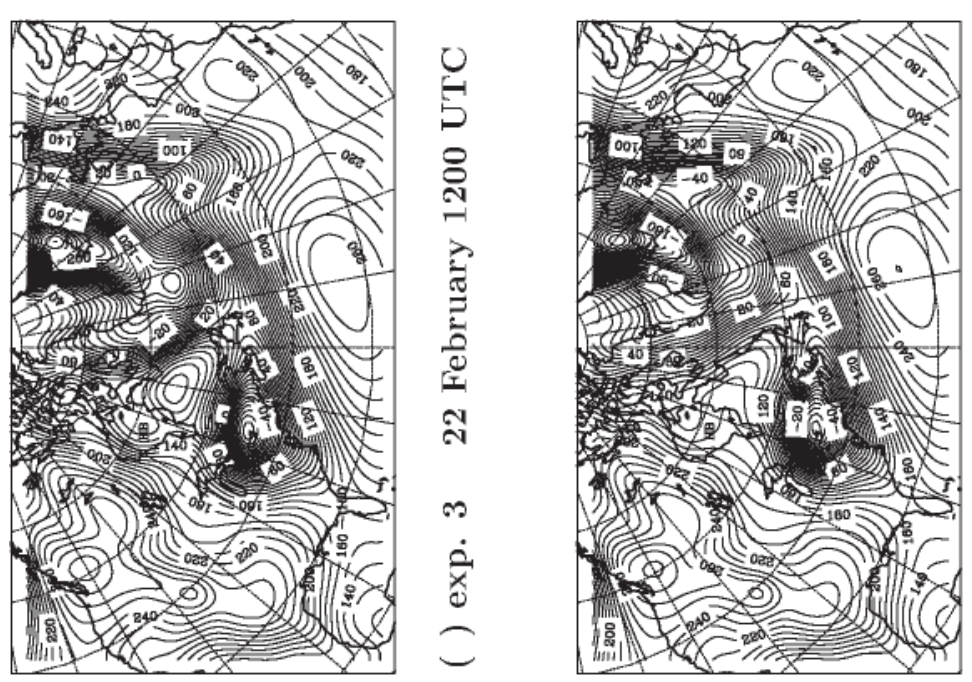

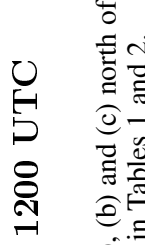

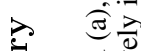

ซี ฮ리

o

I

N

กิ

चै

o 5.

$\therefore$ ज

爻

o 0

(4)

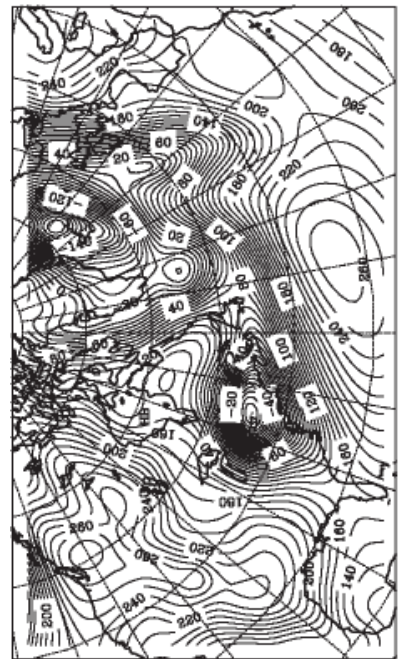

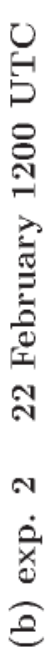

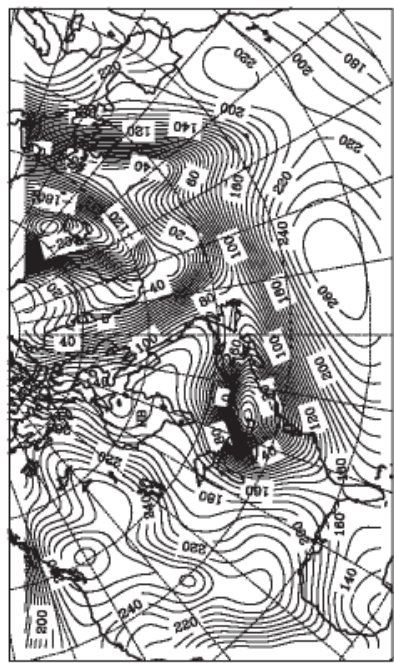

$\Xi$

( )

兒 至

$\checkmark$ 政

증

근

$\rightarrow \quad$

ีำ

는

I

ก

ฮิ

10 은

․

网 离

(e)

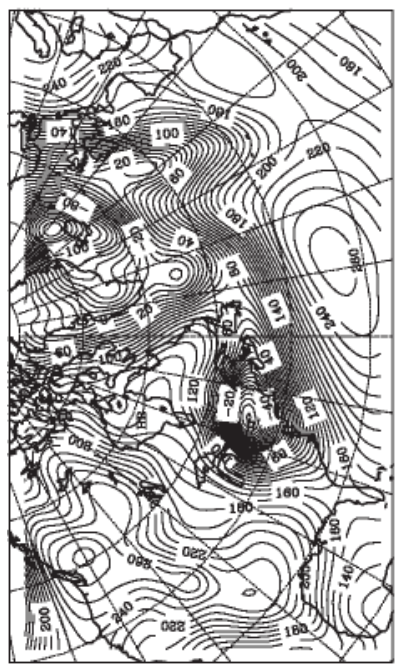

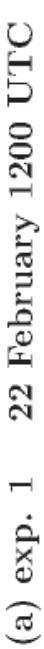

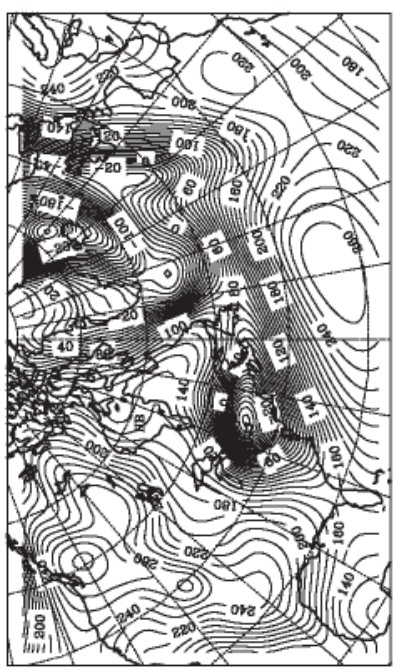

( )

舅恶

○

8 ठัำ

ก

7 दे

ते 8

3 응

능 प्त

0

)

สิ

$+\quad$ 苛

- bे

ํํㅇ

ฮ 


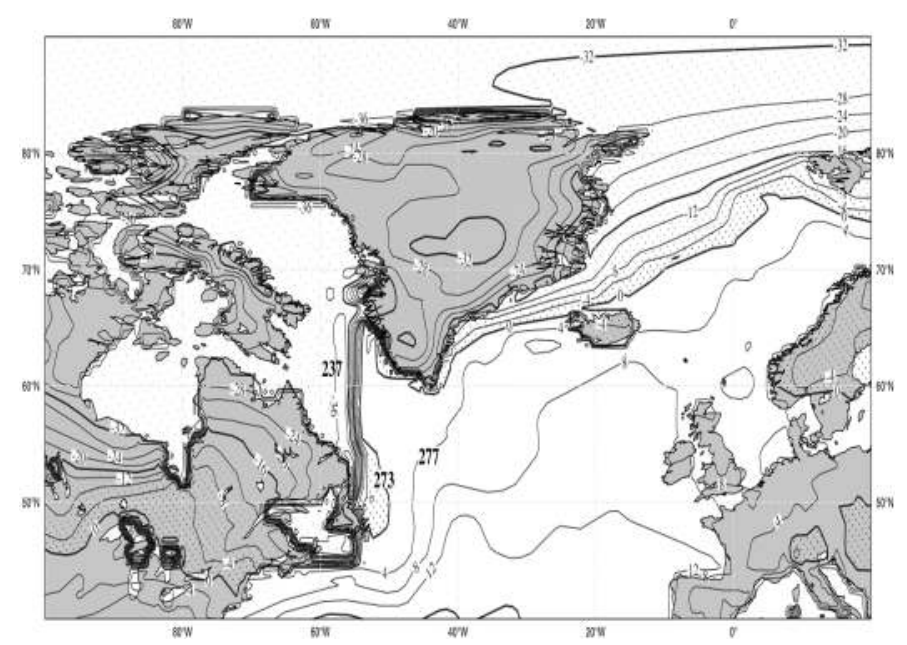

Figure 11. Modified surface temperature field $\left({ }^{\circ} \mathrm{C}\right.$ and $\mathrm{K}$ in bold, with contour interval 4 deg, stippled for temperatures below $273 \mathrm{~K})$ at $0000 \mathrm{UTC}$ on 21 February 1997 . Over the ocean, $238 \mathrm{~K}\left(-35^{\circ} \mathrm{C}\right)$ is imposed north of $45^{\circ} \mathrm{N}$, west of $55^{\circ} \mathrm{W}$.

to 'freeze' the development of the low (minimized surface fluxes) when it is over the simulated ice shelf. This may explain the smaller extent of the geopotential minimum in experiment 4. For experiment 5 (Fig. 10(e)), there is no isolated geopotential minimum in the region of interest but the low is clearly present. It reaches approximately $-60 \mathrm{~m}$ (Table 2). For experiment 6 (Fig. 10(f)), again there is no isolated geopotential minimum in the region of interest but the low is present, and reaches approximately $-30 \mathrm{~m}$ (Table 2). Compared to experiment 1, the absence of an isolated geopotential minimum in experiments 5 and 6 may be attributed to the great influence of the Icelandic low (Table 2), which reaches $-270 \mathrm{~m}$ with the real surface temperature (experiments 5 and 6 ), whereas it is only $-170 \mathrm{~m}$ with uniformly cold SST north of $45^{\circ} \mathrm{N}$ in experiment 1 . $1000 \mathrm{hPa}$ geopotential heights of the Icelandic low for experiments 1, 2 and 3 (Table 2) show that the warmer the SST, the deeper the Icelandic low. Consequently, the deeper the Icelandic low is, the further its influence extends towards south Greenland and consequently the greater is the interaction with the low 44 . To some extent, the Icelandic low provides the environment in which low 44 develops. Therefore, if we speculate from Table 2 that both low 44 and the Icelandic low are sensitive to changes in SST, we might conclude that the SST influence on low 44 is both direct (locally) and indirect (through Icelandic low deepening).

These results are summarized in Fig. 12 in which the $1000 \mathrm{hPa}$ geopotential minima associated with low 44 are plotted every 3 hours for experiments $0_{a}$ and 1 to 6 . For each experiment, we assumed a linear variation of the $1000 \mathrm{hPa}$ geopotential minimum during the forecast, and deduced the corresponding 'equivalent deepening rate'. The reference forecast (experiment $0_{\mathrm{a}}$ ) gives a deepening of $25 \mathrm{~m}(24 \mathrm{~h})^{-1}$. For experiment $1\left(238 \mathrm{~K} \mathrm{SST}\right.$ north of $\left.45^{\circ} \mathrm{N}\right)$, the $1000 \mathrm{hPa}$ geopotential minimum increases and the low weakens at a rate of $-21 \mathrm{~m}(24 \mathrm{~h})^{-1}$. This weakening can be attributed to the imposed SST $(238 \mathrm{~K})$ lower than the surface temperature of the continent in the region of Labrador (at $55^{\circ} \mathrm{N}, 70^{\circ} \mathrm{W}$, the surface temperature is approximately $256 \mathrm{~K}$ (Fig. 4)). For experiment $2\left(256 \mathrm{~K} \mathrm{SST}\right.$ north of $\left.45^{\circ} \mathrm{N}\right)$, the temporal evolution of the $1000 \mathrm{hPa}$ geopotential minimum is weak $\left(-4 \mathrm{~m}(24 \mathrm{~h})^{-1}\right)$. This can be attributed to a near-absence 


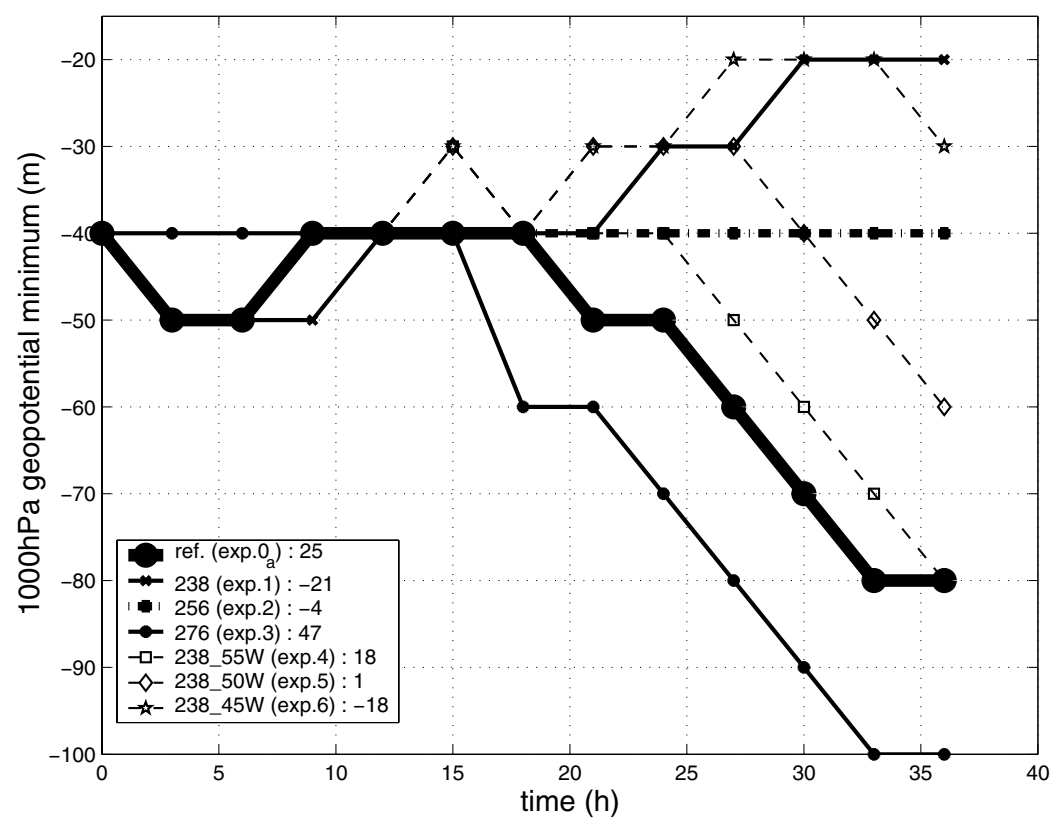

Figure 12. Evolution of $1000 \mathrm{hPa}$ geopotential minimum for low 44 in 36-hour forecasts (from 0000 UTC on 21 February) with various surface temperatures corresponding to experiments $0_{\mathrm{a}}$ and 1 to 6 in Tables 1 and 2 . The boldest solid line is the reference forecast. Other bold lines are for forecasts with SST modified everywhere north of $45^{\circ} \mathrm{N}$. Thin lines are for forecasts with SST modified north of $45^{\circ} \mathrm{N}$ and west of a given longitude.

The deepening rate $\left(\mathrm{m}(24 \mathrm{~h})^{-1}\right.$, positive for deepening) for each experiment is shown in the legend.

of temperature transition between the continent and the ocean. Experiment 3 (276 K SST north of $45^{\circ} \mathrm{N}$ ) shows a deepening of $47 \mathrm{~m}(24 \mathrm{~h})^{-1}$, greater than for the reference forecast. The main difference between experiment 3 and the reference is the absence of the ice shelf in experiment 3 . The transition between low surface temperature and warmer ocean coincides with the coast line, so it is more to the west in experiment 3. Consequently, the low begins to deepen at 1500 UTC on 21 February in experiment 3, three hours sooner than for the reference forecast. In experiments 4, 5 and 6, the SST is modified north of $45^{\circ} \mathrm{N}$ and west of $55^{\circ} \mathrm{W}, 50^{\circ} \mathrm{W}$ and $45^{\circ} \mathrm{W}$, respectively. In these cases, the $1000 \mathrm{hPa}$ geopotential minimum evolution of the low 44 is very similar: a slight filling or very little evolution when the low is over an imposed cold surface and a deepening corresponding to the realistic SST, warmer than the western $238 \mathrm{~K}$ imposed SST. The surface low deepening is delayed when the ice-shelf limit is moved eastwards. For experiment 4 , the deepening rate is $18 \mathrm{~m}(24 \mathrm{~h})^{-1}$, weaker than for the reference which is in agreement with the comments on Fig. 10(d). For experiment 5(6), the $238 \mathrm{~K} / \mathrm{real}$ SST transition occurs at 0300 (0900) UTC on 22 February, when the imposed ice shelf is located at $50^{\circ} \mathrm{W}\left(45^{\circ} \mathrm{W}\right)$. This shifting of the deepening of the low appears clearly in the increase of the deepening rate: $1 \mathrm{~m}(24 \mathrm{~h})^{-1}$ for experiment 5 and $-18 \mathrm{~m}(24 \mathrm{~h})^{-1}$ for experiment 6 . As a consequence, the further east the surface transition is, the later the deepening occurs. Except for experiments 1 and 2, there are two stages in the evolution: the first stage corresponds to the position of the low over the land; the second stage corresponds to the position of the low over the ocean. Although only the SST has been modified, there are weak variations between experiments in the first stage. This can be explained by the influence of Hudson Bay and the Labrador Sea 
when the low is over north Quebec and Labrador in the first stage. The sensitivity to the location of the limit between lower surface temperature (ice shelf) and higher surface temperature (open ocean) is therefore a significant factor in modifying the cyclogenesis life cycle in this area.

\section{CONCLUSION}

A cold-air cyclogenesis has been studied using a PV inversion method associated with the French operational ARPEGE model. Forecasts of this model are in good agreement with reanalyses, which allowed sensitivity tests to be performed, and the inversion method is well suited to our objectives. This cold-air cyclogenesis corresponds to one of the two Type C FASTEX IOP cases listed by Deveson et al. (2002). Both highlevel and surface influences on cyclogenesis have been identified using the PV inversion tool.

First, the triggering role of the coherent tropopause disturbance on cyclogenesis was studied. PV inversions performed at the initial time of the model simulation aimed at testing the impact of the presence or absence of the PV structure during the course of the model simulation. Whereas the reference forecast reproduces the IOP 18 surface low very well, in the PV-modified forecast the surface low dies and there is no cyclogenesis above the North Atlantic. We conclude that the upper-level tropopause coherent structure was essential for the cyclogenesis of IOP 18. This altitudedependance result is in agreement with the findings of Deveson et al. (2002).

Next, we went further by investigating the surface temperature effect on the intensification of the cyclogenesis. The PV inversion method was used to test the sensitivity to the surface temperature of the penetrating depth of the upper-level forcing. A study of vertical motions associated with the PV anomaly suggests that the baroclinic interaction of the tropopause disturbance maintains the surface low without further development as long as the surface temperature is homogeneous. Then, we investigated the effects of surface temperature modifications on vertical motions associated with the PV coherent structure. First, we imposed a $238 \mathrm{~K} \mathrm{SST}$ north of $45^{\circ} \mathrm{N}$ which corresponds to the observed surface temperature north of Canada. Comparison of vertical motions associated with the upper-level PV structure in the cases of the reference surface temperature and with constant $(238 \mathrm{~K})$ value shows that: (i) the vertical velocity dipole is clearly associated with the tropopause disturbance, (ii) downward vertical motions are similar in both cases, (iii) upward vertical motions are smaller in the case of the imposed low surface temperature than in the real case, and (iv) the upward part of the vertical motion dipole and the surface low are collocated. Simulations of various homogeneous surface temperatures show that the warmer the surface, the deeper the surface low.

Finally, three tests on the relationship between the location of a meridional surface temperature gradient $\left(55^{\circ} \mathrm{W}, 50^{\circ} \mathrm{W}, 45^{\circ} \mathrm{W}\right)$ and the deepening of the surface low were performed. The result is that if the simulated transition between ice shelf and open sea is further to the east, then the longer is the delay in the deepening of the surface low. We conclude that the sea-ice transition indeed acts as a surface-level precursor for the intensification of the cyclogenesis. Multi-phase cyclogenesis life cycles have already been found in IOP 17 FASTEX studies (Cammas et al. 1999; Mallet et al. 1999). We found a great influence of the Icelandic low deepening on low 44 development. This suggests the SST influence on low 44 might be both direct (locally) and indirect (through Icelandic low modification). This speculation might however deserve to be better documented in a further study. 


\section{ACKNOWLEDGEMENTS}

The authors are particularly grateful to Alain Joly and Keith Browning for their invaluable and enthusiastic support of FASTEX. We thank Ryad Elkhatib and Eric Bazile for their help in the ARPEGE data processing. FASTEX has been supported by Institut National des Sciences de l'Univers/Programme Atmosphère et Océan à Moyenne Échelle, and by the European Commission under contract ENV4-CT96-0322. Computer resources were allocated by Météo-France.

Alpert, P. M., Tsidulko, M. and Stein, U.

Ayrault, F.

Baehr, C., Pouponneau, B., Ayrault, F. and Joly, A.

Bergeron, $\mathrm{T}$.

Cammas, J.-P., Pouponneau, B., Desroziers, G., Santurette, P., Joly, A., Arbogast, P.,

Mallet, I., Caniaux, G. and Mascart, P.

Chaigne, E. and Arbogast, P.

Chang, E. K. M.

Courtier, P., Freydier, C.,

Geleyn, J.-F., Rabier, F. and Rochas, $\mathrm{M}$.

Davies-Jones, R.

Davis, C. A. and Emanuel, K.

Desroziers, G., Pouponneau, B., Thépaut, J.-N., Janisková, M. and Veersé, F.

Desroziers, G., Hello, G. and Thépaut, J.-N.

Deveson, A. C. L., Browning, K. A. and Hewson, T. D.

Donnadille, J., Cammas, J.-P., Mascart, P., Lambert, D. and Gall, R.

Donnadille, J., Cammas, J.-P., Mascart, P. and Lambert, D.

Emanuel, K. A.

Ertel, H

Fourrié, N., Claud, C., Donnadille, J., Cammas, J.-P., Pouponneau, B. and Scott, N.

Griffiths, M., Thorpe, A. and Browning, $\mathrm{K}$.

Hoskins, B. J., McIntyre, M. E. and Robertson, A. W.

\section{REFERENCES}

1995 Can sensitivity studies yield comparisons for the effects of several processes? J. Atmos. Sci., 52, 597-601

1998 'Environnement, structure et évolution des dépressions météorologiques: réalité climatique et modèle type'. $\mathrm{PhD}$ thesis, University of Toulouse III, France

1999 Dynamical characterization of the FASTEX cyclogenesis cases. Q. J. R. Meteorol. Soc., 125, 3469-3494

1954 Reviews of tropical hurricanes. Q. J. R. Meteorol. Soc., 80, 131-164

1999 FASTEX IOP17 cyclone: Introductory synoptic study with field data. Q. J. R. Meteorol. Soc., 125, 3393-3414
2000

2000

1991

1999

2003

2002

2001a

$2001 b$

1994

1942

2000

2000

1985
Multiple potential vorticity inversions in two FASTEX cyclones. Q. J. R. Meteorol. Soc., 126, 1711-1734

Wave packets and life cycles of troughs in the upper troposphere: Examples from the southern hemisphere summer season of 1984/85. Mon. Weather Rev., 128, 25-50

'The ARPEGE project at Météo-France'. Pp. 193-231 in Proceedings of ECMWF seminar on numerical methods in atmospheric models, ECMWF, Reading, UK

The frontogenetic forcing of secondary circulations. Part I: The duality and generalization of the Q vector. J. Atmos. Sci., 48, 497-509

Potential vorticity diagnostics of cyclogenesis. Mon. Weather Rev., 119, 1929-1953

Four-dimensional variational analyses of FASTEX situations. Part II: Use of additional observations. Q. J. R. Meteorol. Soc., 125, 3339-3358

Four-dimensional reanalyses of FASTEX. Q. J. R. Meteorol. Soc., 129, 1301-1315

A classification of FASTEX cyclones using a height-attributable quasi-geostrophic vertical-motion diagnostic. $Q . \quad J . R$. Meteorol. Soc., 128, 93-117

A very deep tropopause fold. Part I: Synoptic description and modelling. Q. J. R. Meteorol. Soc., 127, 2247-2268

FASTEX IOP18: A very deep tropopause fold: Part II: QG-omega diagnoses. Q. J. R. Meteorol. Soc., 127, 2269-2286

'Sea-air heat transfer effects on extratropical cyclones.' In Proceedings of the conference on the life cycles of extratropical cyclones, Bergen, Norway, 27 June to 1 July, 1994. Available from the University of Bergen, Norway

Ein neuer hydrodynamischer Wirbelsatz. Meteorol. Z., 59, 271-281

Use of TOVS observations for the identification of tropopauselevel thermal anomalies. Q. J. R. Meteorol. Soc., 126, 1473-1494

Convective destabilisation by a tropopause fold diagnosed using potential vorticity inversion. Q. J. R. Meteorol. Soc., 126, 125-144

On the use and significance of isentropic potential vorticity maps. Q. J. R. Meteorol. Soc., 111, 877-946 
Joly, A., Browning, K. A., Bessemoulin, P.,

Cammas, J.-P., Caniaux, G., Chalon, J.-P., Clough, S. A., Dicks, R., Emanuel, K. A., Eymard, L., Lalaurette, F., Gall, R., Hildebrand, P. H., Jorgensen, D.,

Langland, R. H., Lemaitre, Y., Mascart, P., Moore, J. A., Persson, P. O. G., Roux, F., Shapiro, M. A., Snyder, C., Toth, Z. and Wakimoto, R.

Kleinschmidt, E.

Mallet, I., Arbogast, P., Baehr, C., Cammas, J.-P. and Mascart, P.

Neiman, P. J. and Shapiro, M. A.

Nielsen-Gammon, J. W.

Petterssen, S., Dunn, G. E. and Means, L. L.

Petterssen, S. and Smebye, S. J.

Rossby, C. G.

Thorpe, A. J.

Uccellini, L. W.

Whitaker, J. S. and Barcilon, A.
1999

Overview of the field phase of the Fronts and Atlantic StormTrack Experiment (FASTEX) project. Q. J. R. Meteorol. Soc., 125, 3131-3164

1950a Über Aufbau und Entstehung von Zyklonen, I Teil. Meteorol. Rundschau, 3, 1-6

1950b Über Aufbau und Entstehung von Zyklonen, II Teil. Meteorol. Rundschau, 3, 54-61

1999 Effects of cloud diabatic heating on the early development of the FASTEX IOP17 cyclone. Q. J. R. Meteorol. Soc., 125, 3439-3467

1993 The life cycle of an extratropical marine cyclone. Part I: Frontalcyclone evolution and thermodynamic air-sea interaction. Mon. Weather Rev., 121, 2153-2176

2001 'The PV Bible: Applications in atmospheric dynamics.' In Proceedings of 13th AMS conference on atmospheric and oceanic fluid dynamics, Breckenridge, 4-8 June, American Meteorol. Soc., Boston, USA

1955 Report on an experiment in forecasting of cyclone development. J. Meteorol., 12, 58-67

1971 On the development of extratropical cyclones. Q. J. R. Meteorol. Soc., 97, 457-482

1940 Planetary flow patterns in the atmosphere. Q. J. R. Meteorol. Soc., 66 supplement, 68-87

1997 Attribution and its application to mesoscale structure associated with tropopause folds. Q. J. R. Meteorol. Soc., 123, 2377-2399

1990 Processes contributing to the rapid development of extratropical cyclones. Pp. 81-105 in Extratropical cyclones: The Erik Palmén Memorial Volume, American Meteorol. Soc., Boston, USA

1992 Genesis of mobile troughs in the upper westerlies. J. Atmos. Sci. 49, 2097-2107 